\title{
Nanostructured Crystals: Unique Hybrid Semiconductors Exhibiting Nearly Zero Uniaxial and Tunable Thermal Expansion Behavior
}

\author{
Jing Li*, Wenhua Bi, Wooseok Ki, Xiaoying Huang, Srihari Reddy \\ Department of Chemistry and Chemical Biology, Rutgers University, 610 Taylor \\ Road, Piscataway, NJ 08854 \\ RECEIVED DATE (automatically inserted by publisher); jingli@rci.rutgers.edu
}

\section{Supporting Information}

S.1. Synthesis and Crystal Growth.

S.2. Unit Cell Constants Refined from Fall Data Sets at 95, 195 and 295K for 1-3, 5; and 155, 225, and 295K for 4.

S.3. Changes in the Unit Cell Constants as a Function of Temperature.

S.4. Linear Regression Plots for $L_{3}$.

S.5. Linear Regression Plots for $L_{1}$ and $L_{2}$.

S.6. Figure 1 and Figures 2b-c (Enlarged Version).

S.7. Optical Absorption Spectra of 1-5.

S.8. Structure Comparison of $\alpha$-[ZnTe(en $\left.)_{0.5}\right]$ and $\beta$-[ZnTe(en $\left.)_{0.5}\right]$

S.9. References 


\section{S.1. Synthesis and Crystal Growth}

All reactions were carried out under solvothermal conditions in sealed Teflon-lined stainless autoclave reactors $(23 \mathrm{~mL})$. After being cooled to room temperature, the products were washed with distilled water and 95\% ethanol followed by drying in anhydrous ethyl ether.

Synthesis of $\boldsymbol{\alpha}$-[ZnTe$\left.\left(\boldsymbol{N}_{2} \boldsymbol{H}_{4}\right)_{0.5}\right]$ (1). Solvothermal reactions of $\mathrm{ZnO}$ (1mmol), Te (1mmol) and hydrazine anhydrous $\left(\mathrm{N}_{2} \mathrm{H}_{4}, 1 \mathrm{~mL}\right)$ and methylamine $(\mathrm{ma}, 1 \mathrm{~mL})$ at $180^{\circ} \mathrm{C}$ for 8 days afforded nearly colorless needle-like crystals of $\mathbf{1}$.

Synthesis of $\boldsymbol{\alpha}$-[ZnTe(en $\left.)_{0.5}\right]$ (2). Colorless thin plate-like crystals of $\mathbf{2}$ were obtained from reactions of $\mathrm{ZnCl}_{2}(2 \mathrm{mmol})$, Te $(1 \mathrm{mmol})$, and ethylenediamine (en, $\left.4 \mathrm{~mL}\right)$ at $200^{\circ} \mathrm{C}$ for 7 days.

Synthesis of $\alpha$-[ZnTe(pda) $\left.)_{0.5}\right]$ (3). Compound 3 was prepared from reactions of $\mathrm{ZnCl}_{2}$ (2mmol), Te (1mmol), and 1,3-Propanediamine ( $p d a, 5 \mathrm{~mL})$ at $200^{\circ} \mathrm{C}$ for 3 days. After being cooled rapidly under flowing water, colorless thin plate-like crystals were obtained.

Synthesis of $\boldsymbol{\alpha}$-[ZnTe(bda) $\left.)_{0.5}\right]$ (4). Colorless plate-like crystals of 4 were obtained from reactions of $\mathrm{ZnF}_{2}(1 \mathrm{mmol})$, Te (0.5mmol), and 1,4-butanediamine (bda, 3mL) at $200{ }^{\circ} \mathrm{C}$ for 4 days.

Synthesis of $\alpha-\left[\mathrm{ZnTe}(p t d a)_{0.5}\right]$ (5). Colorless plate-like crystals of 5 were obtained from the reactions of $\mathrm{Zn}\left(\mathrm{NO}_{3}\right) 6 \mathrm{H}_{2} \mathrm{O}(0.6 \mathrm{mmol})$, Te $(0.3 \mathrm{mmol})$, and 1,5-pentanediamine (ptda, $\left.2 \mathrm{~mL}\right)$ at $210^{\circ} \mathrm{C}$ for 3 days. 
S.2. Unit Cell Constants Refined from Fall Data Sets at 95, 195 and 295K for 1-3, 5; and 155, 225, and $295 \mathrm{~K}$ for 4.

\begin{tabular}{|c|c|c|c|}
\hline Compounds & R. T. & $195 K$ & $95 K$ \\
\hline $\mathrm{ZnTe}\left(\mathrm{N}_{2} \mathrm{H}_{4}\right)_{0.5}$ & $\begin{array}{c}a=6.9513(8) ; b=6.8316(8) \\
c=13.3114(15)\end{array}$ & $\begin{array}{c}\mathrm{a}=6.9430(7) ; b=6.8165(7) \\
c=13.3065(14)\end{array}$ & $\begin{array}{c}a=6.9206(7) ; b=6.8057(7) \\
c=13.3024(14)\end{array}$ \\
\hline ZnTe(en) $)_{0.5}$ & $\begin{array}{c}\mathrm{a}=7.0755(4) ; b=6.9262(4) \\
c=17.5569(10)\end{array}$ & $\begin{array}{c}\mathrm{a}=7.0574(4) ; b=6.9180(4) \\
c=17.5653(10)\end{array}$ & $\begin{array}{c}\mathrm{a}=7.0408(4) ; b=6.9117(4) \\
c=17.5686(9)(95 \mathrm{~K})\end{array}$ \\
\hline ZnTe(pda) 0.5 & $\begin{array}{c}a=20.2234(13) ; b=7.0701(5) \\
c=6.9016(5)\end{array}$ & $\begin{array}{c}a=20.2376(17) ; b=7.0527(6) \\
c=6.8893(6)\end{array}$ & $\begin{array}{c}\mathrm{a}=20.238(2) ; \mathrm{b}=7.0383(8) \\
c=6.8809(8)(95 \mathrm{~K})\end{array}$ \\
\hline $\mathrm{ZnTe}(\mathbf{b d a})_{0.5}$ & $\begin{array}{c}a=7.0762(3) ; b=6.9279(3) \\
c=22.3575(11)\end{array}$ & $\begin{array}{c}\mathbf{a}=7.0612(5) ; b=6.9197(5) \\
c=22.3706(17)^{*}\end{array}$ & $\begin{array}{c}\mathrm{a}=7.0473(4) ; b=6.9152(4) ; \\
c=22.3865(12)(155 \mathrm{~K}) * *\end{array}$ \\
\hline ZnTe(ptda) $)_{0.5}$ & $\begin{array}{c}a=25.2744(18) ; b=7.0589(5) \\
c=6.9001(5)\end{array}$ & $\begin{array}{c}a=25.2832(19) ; b=7.0437(5) \\
c=6.8882(5)\end{array}$ & $\begin{array}{c}\mathrm{a}=25.314(3) ; b=7.0365(9) \\
c=6.8872(9)(95 \mathrm{~K})\end{array}$ \\
\hline
\end{tabular}

* 225K

** 155K 
S.3. Changes in the Unit Cell Constants as a Function of Temperature.

$\left[\mathrm{ZnTe}\left(\mathrm{N}_{2} \mathrm{H}_{4}\right)_{0.5}\right](\mathbf{1})$

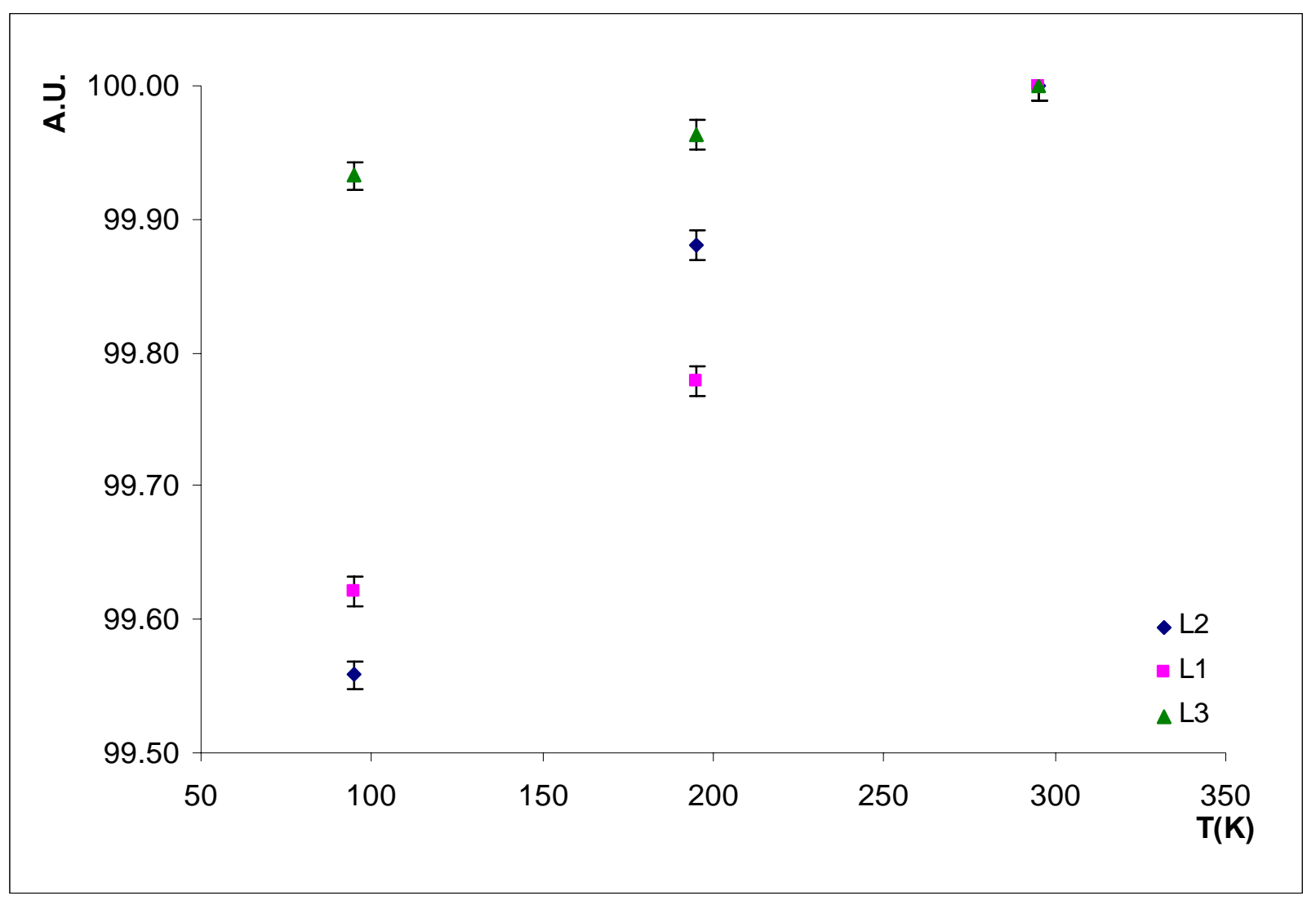


[ZnTe(en) $)_{0.5}$ (2)

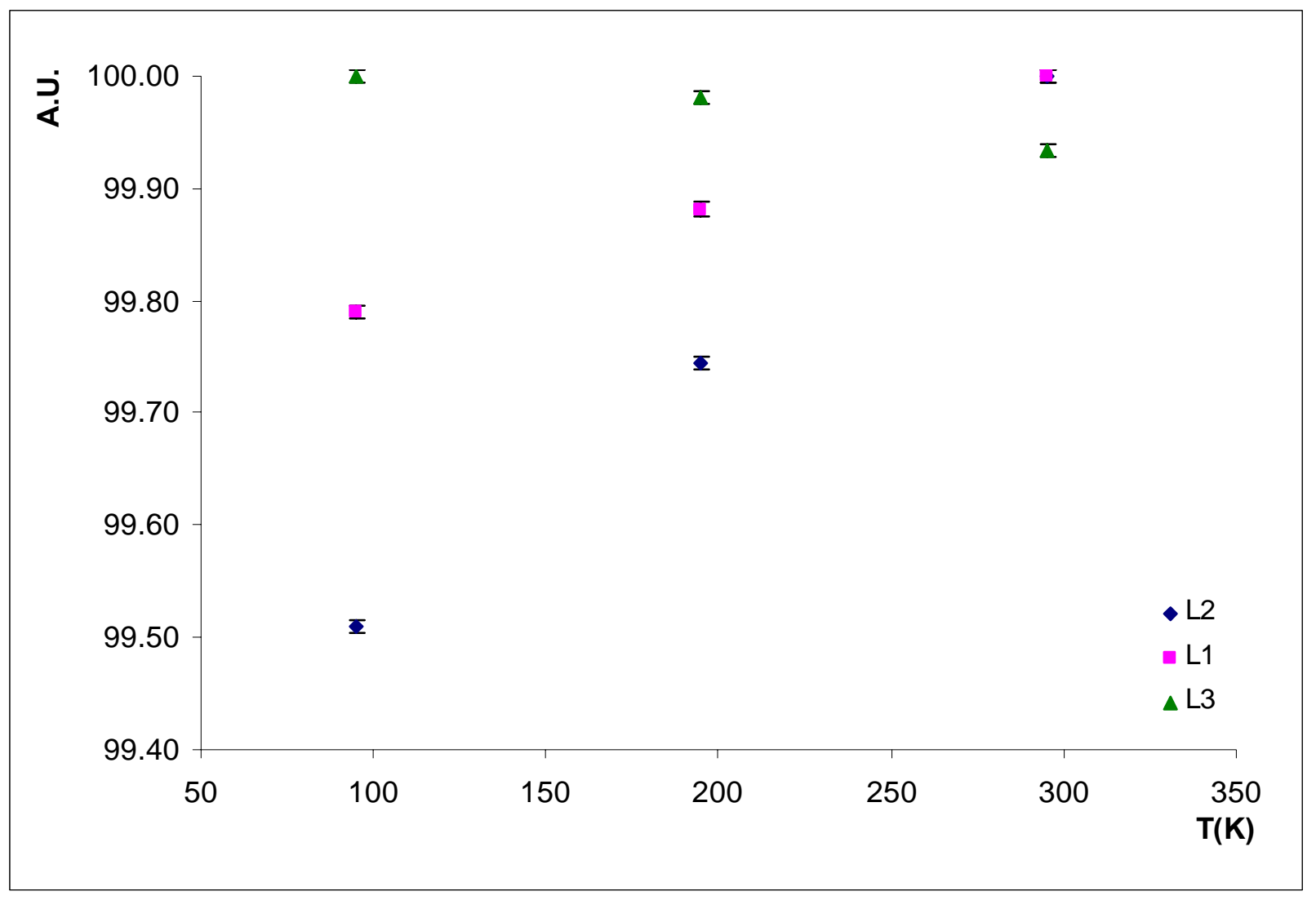


[ZnTe(pda) $\left.{ }_{0.5}\right]$ (3)

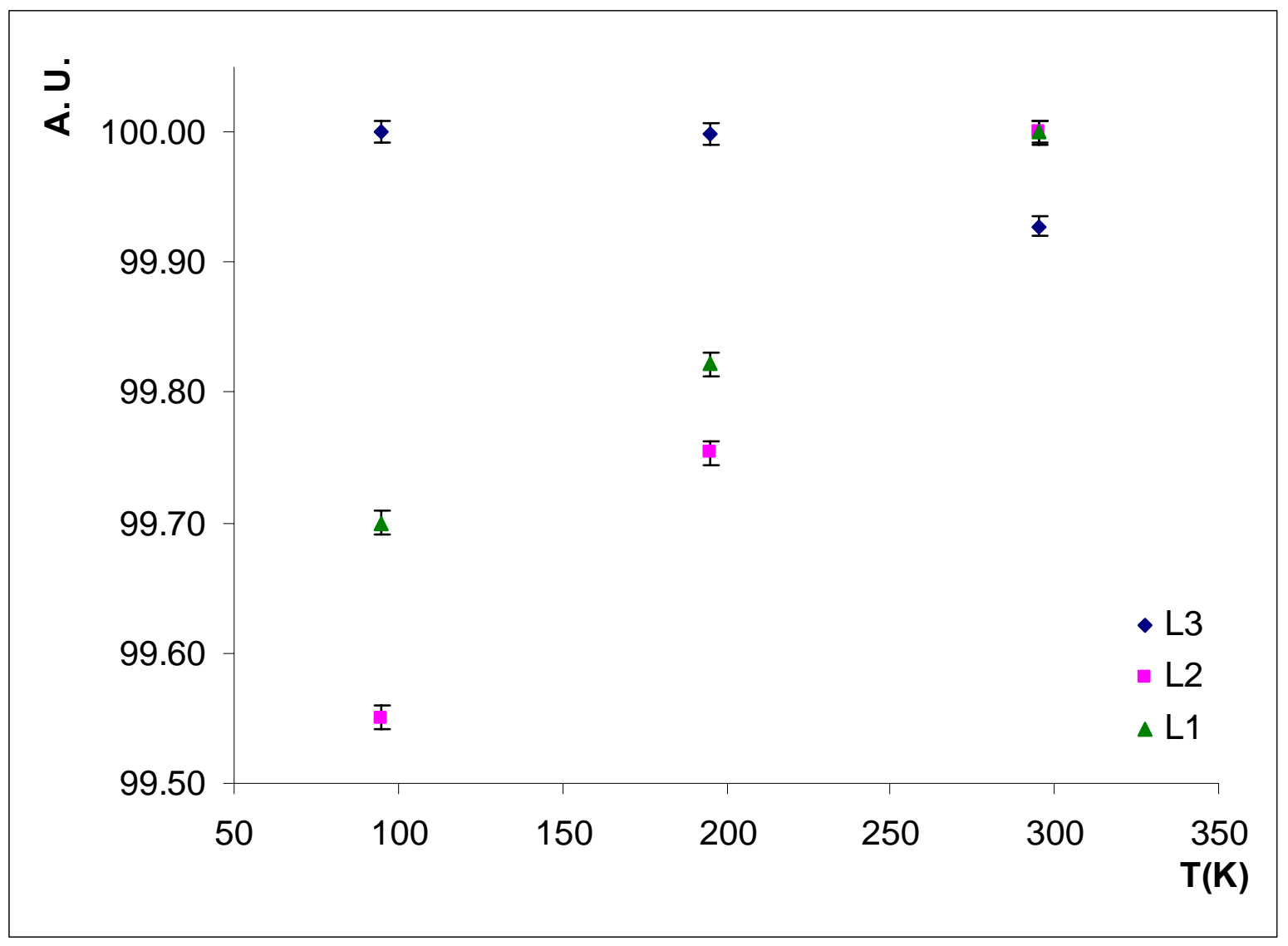


[ZnTe(bda) $\left.)_{0.5}\right]$ (4)

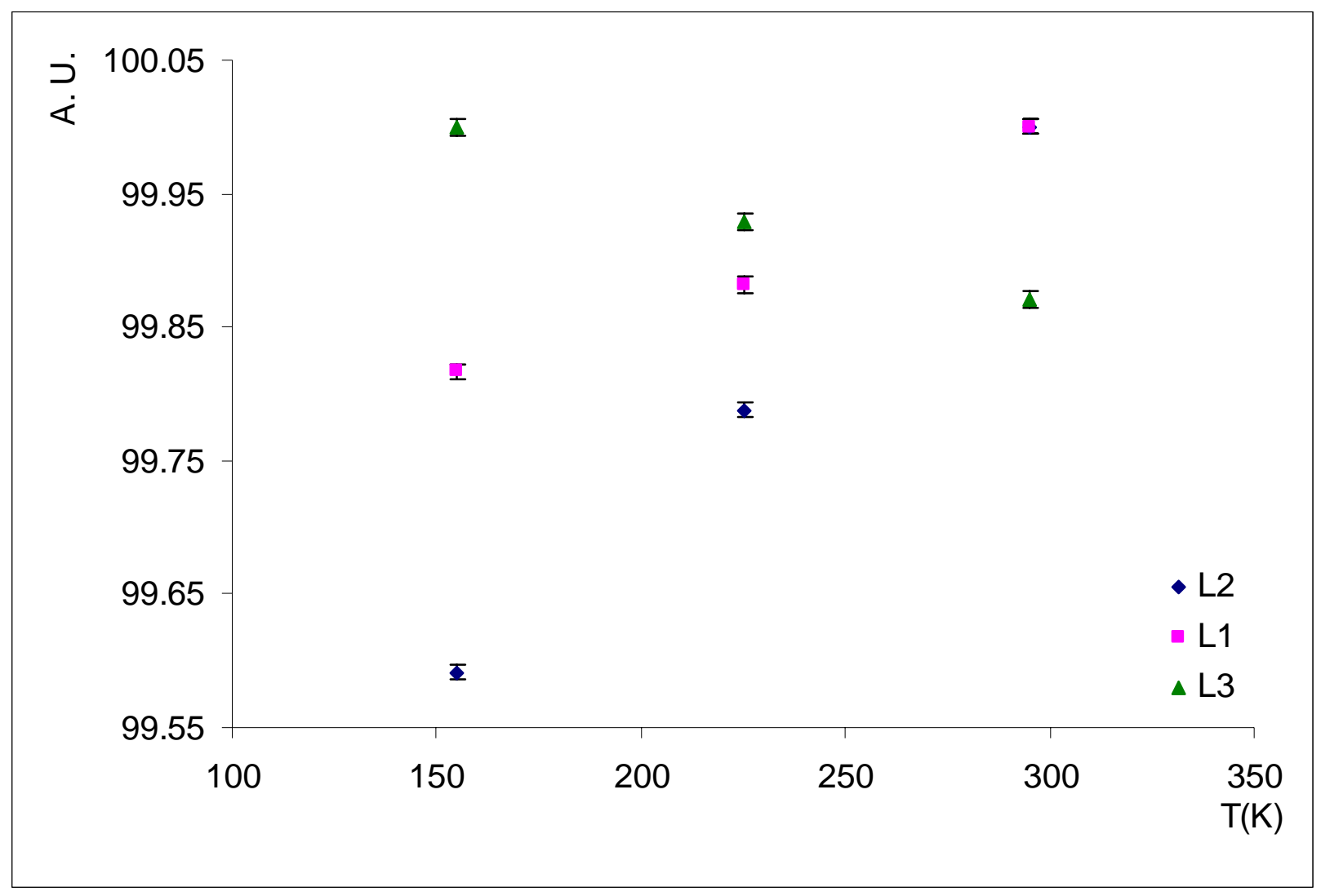


[ZnTe(ptda) $\left.)_{0.5}\right]$ (5)

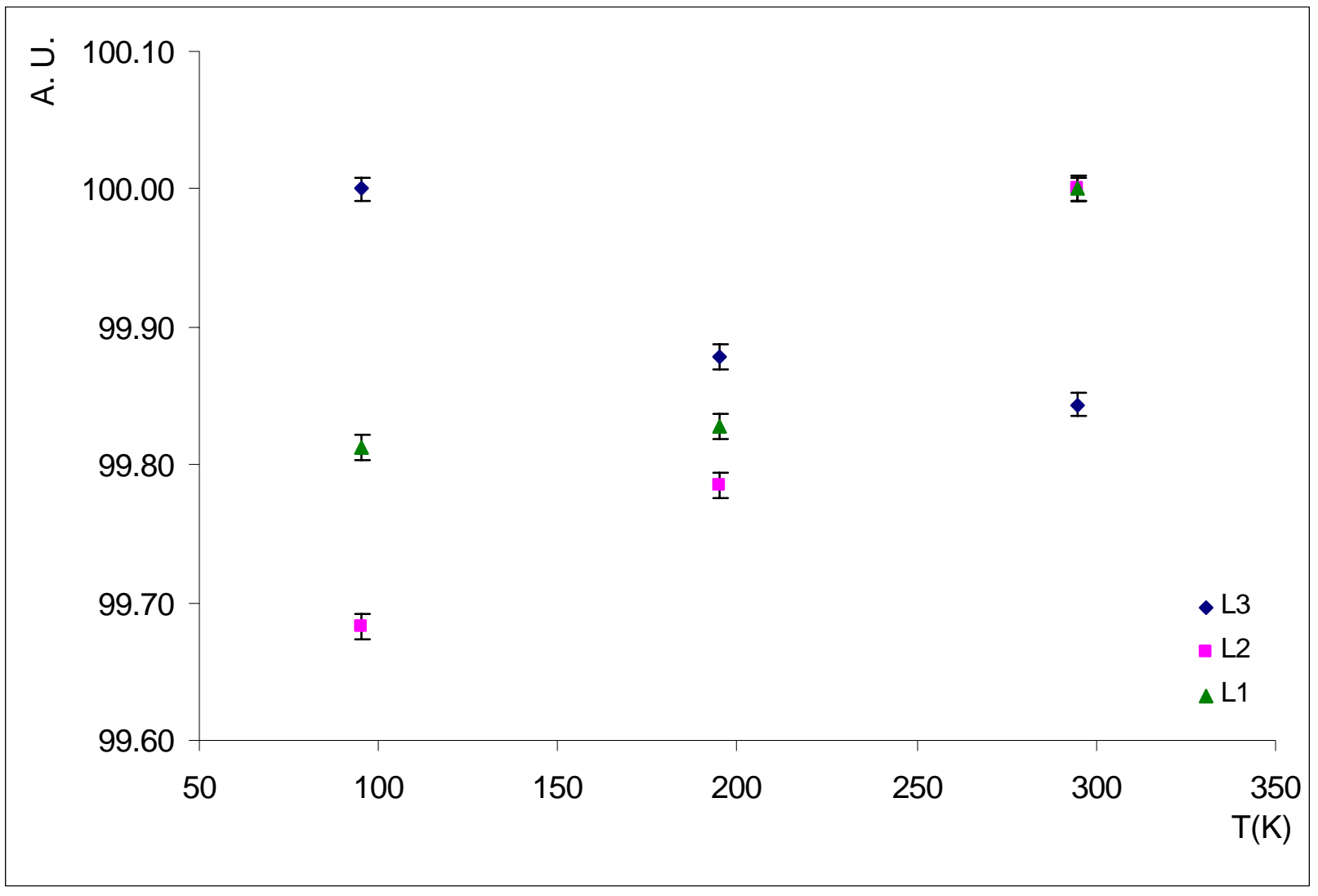


S.4. Linear Regression Plots for $L_{3}$.

$\left[\mathrm{ZnTe}\left(\mathrm{N}_{2} \mathrm{H}_{4}\right)_{0.5}\right](\mathbf{1})$

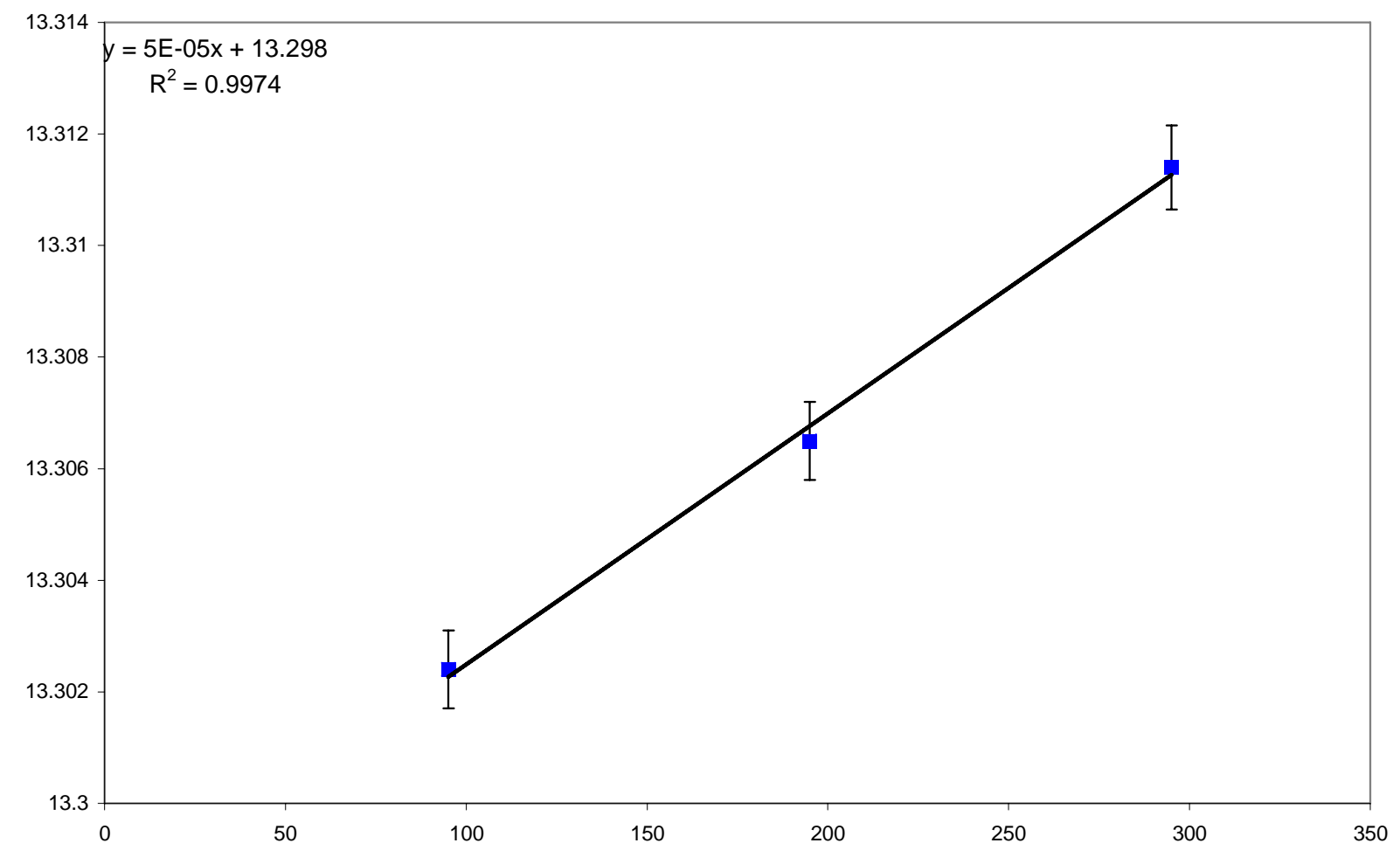


[ZnTe(en) $)_{0.5}$ (2)

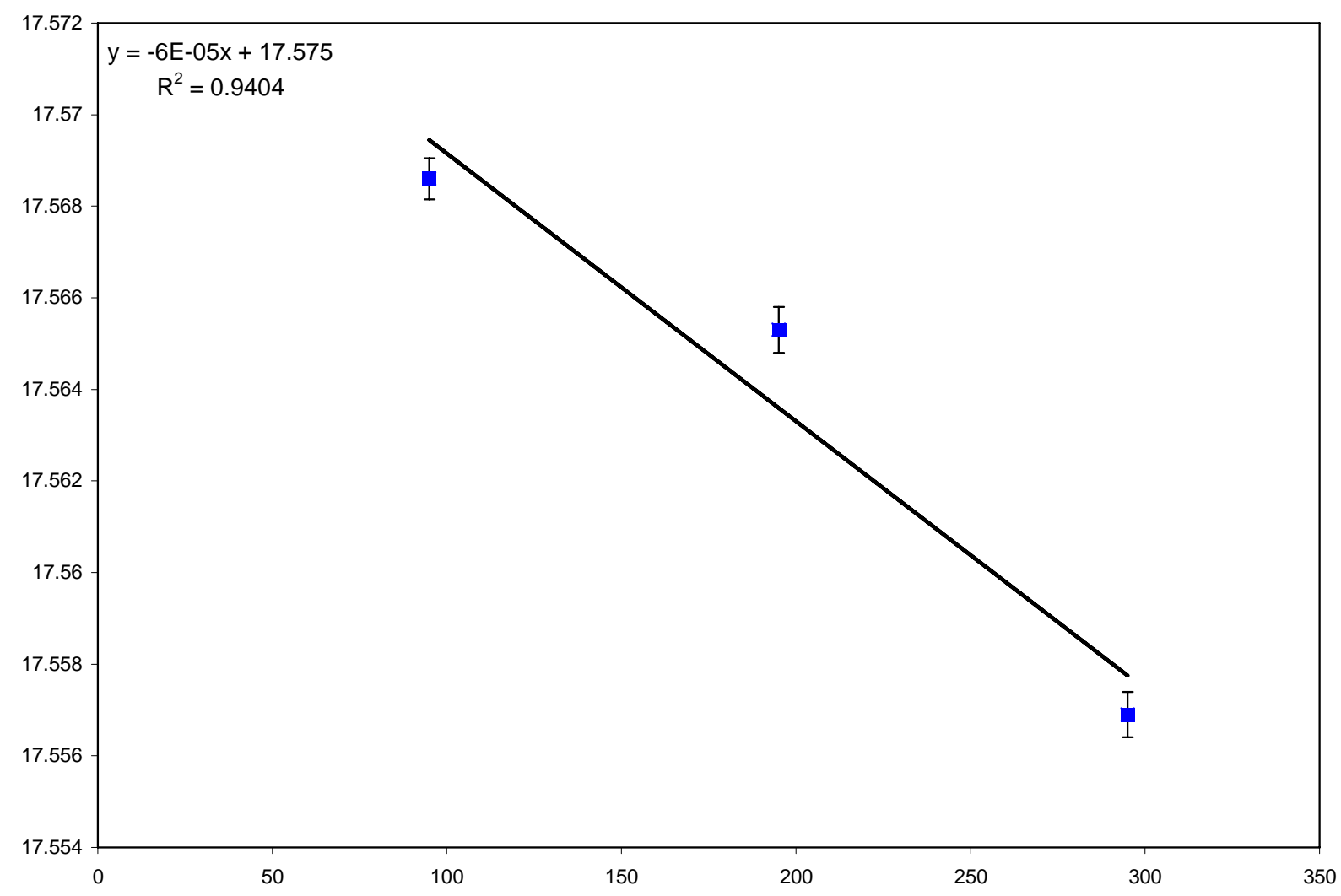


[ZnTe(pda) $\left.)_{0.5}\right]$ (3)

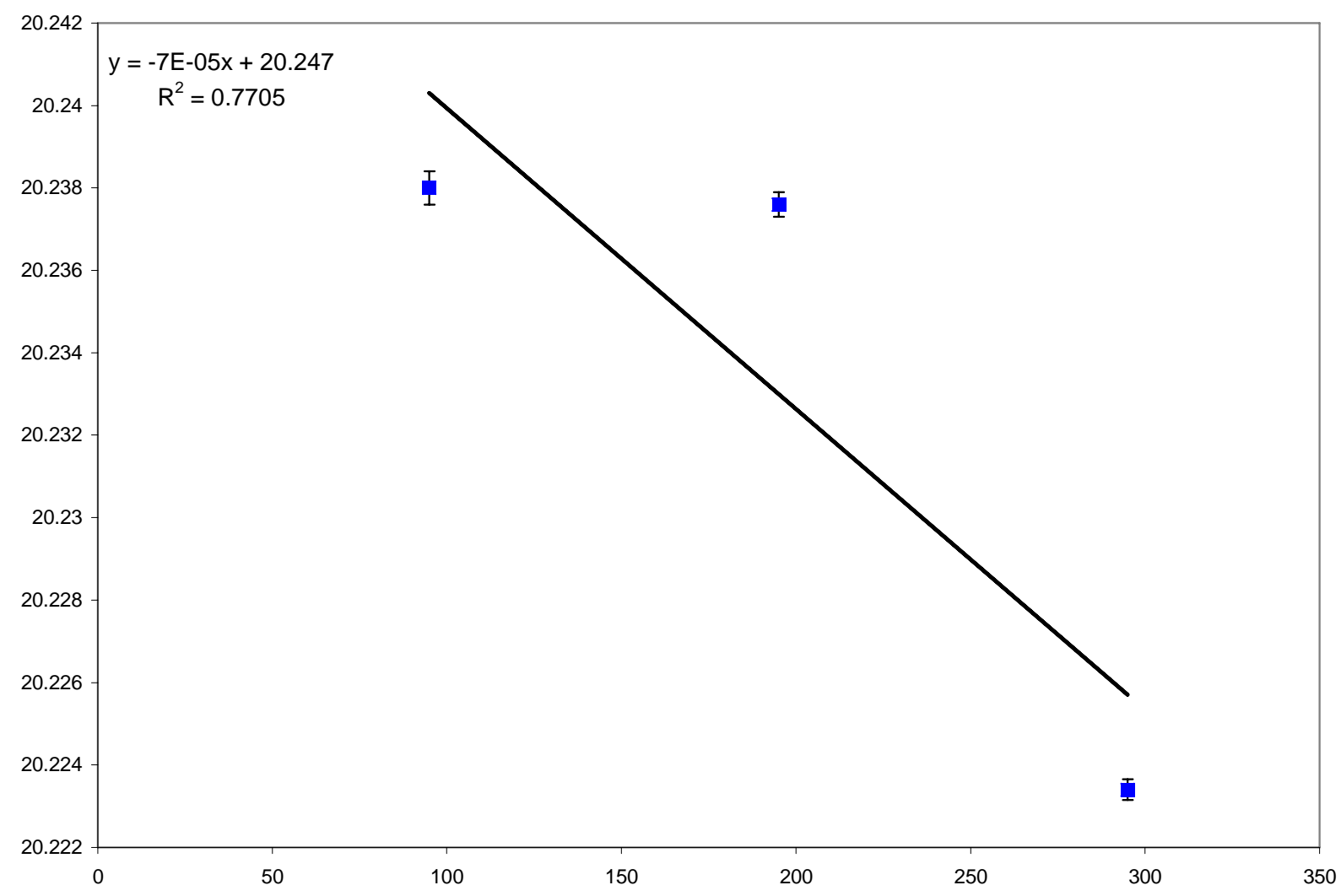


[ZnTe(bda) $)_{0.5}$ (4)

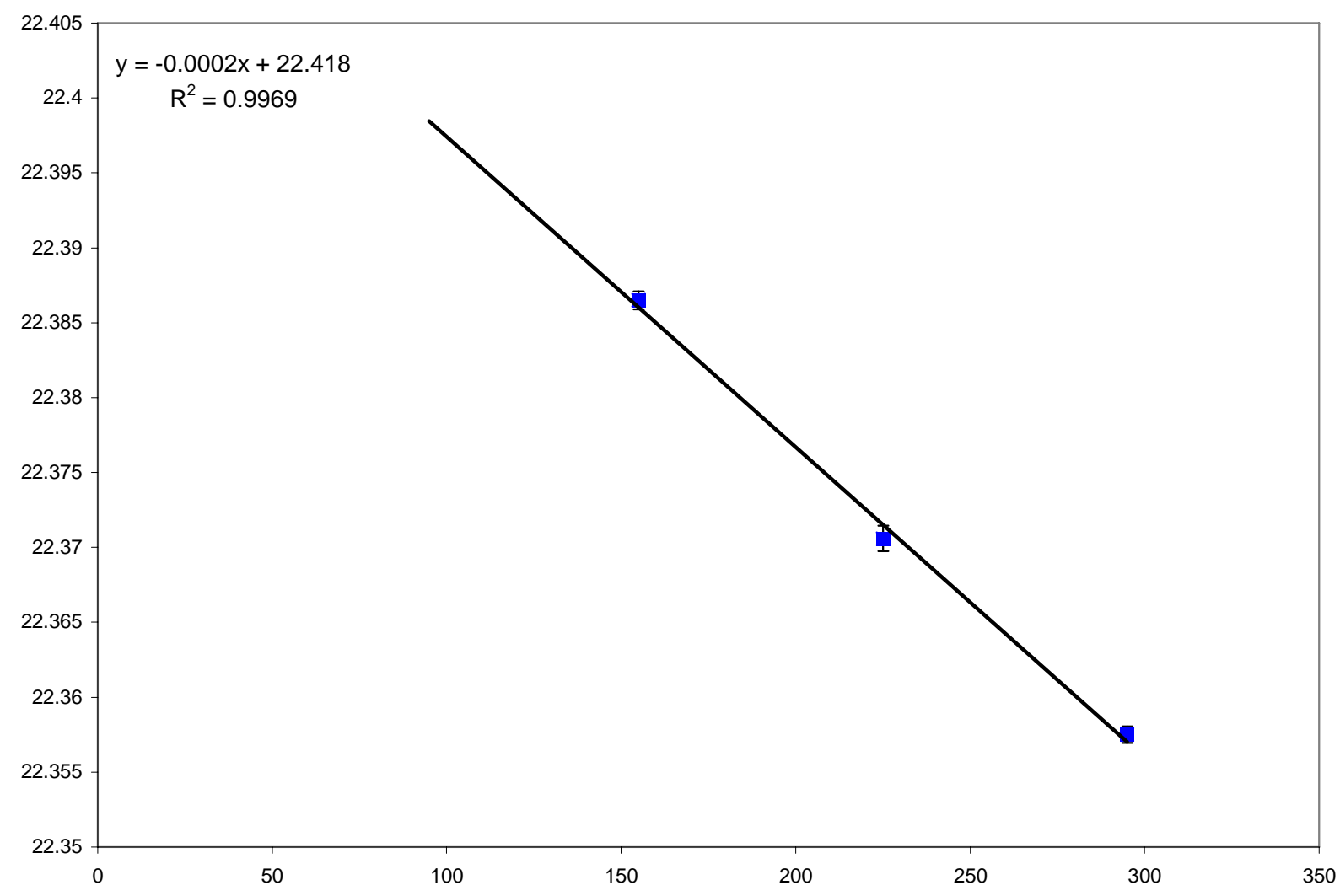


[ZnTe(ptda) $\left.)_{0.5}\right]$ (5)

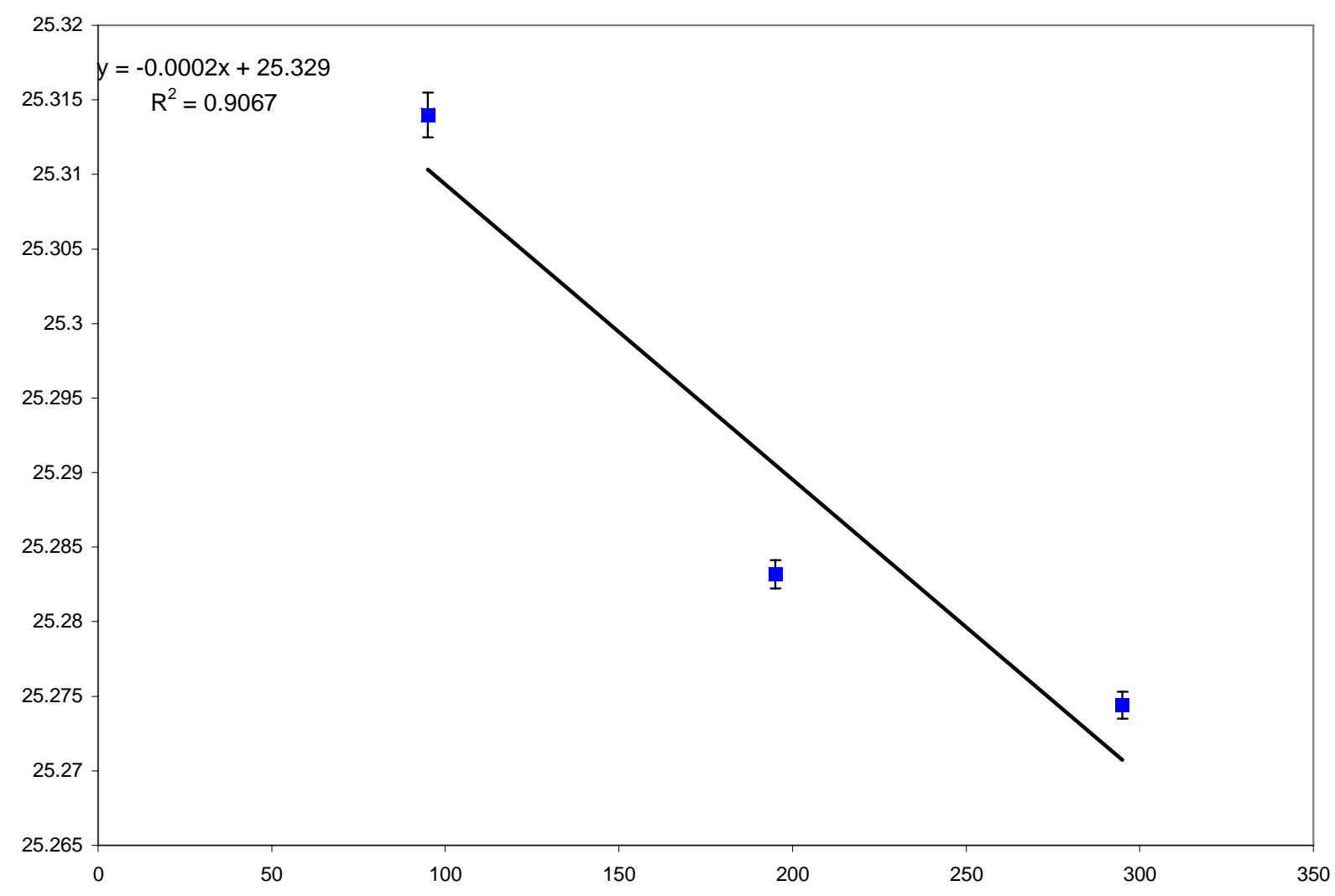


S.5. Linear Regression Plots for $L_{1}$ and $L_{2}$.

$\left[\mathrm{ZnTe}\left(\mathrm{N}_{2} \mathrm{H}_{4}\right)_{0.5}(\mathbf{1})\right.$

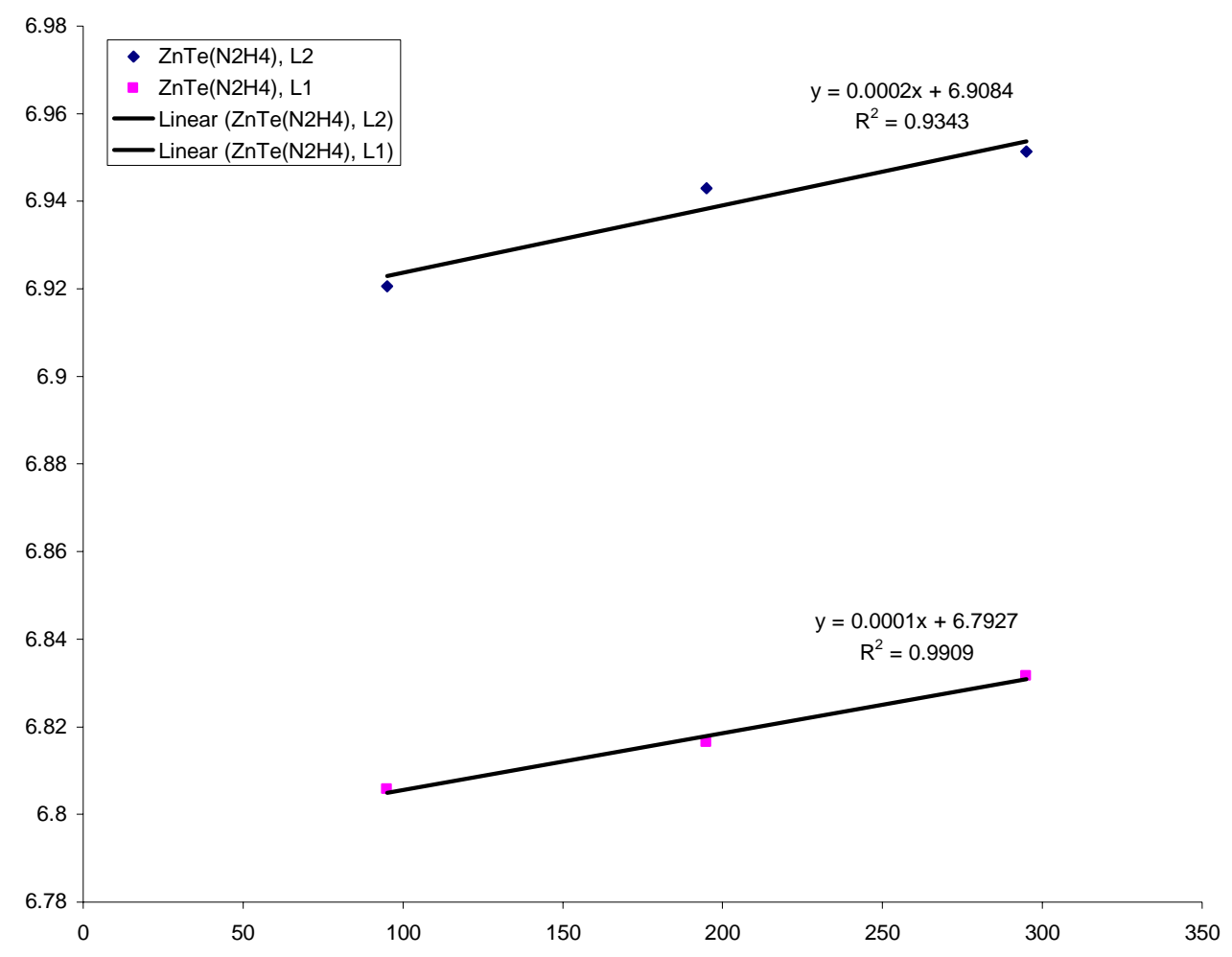


[ZnTe(en) $\left.)_{0.5}\right]$ (2)

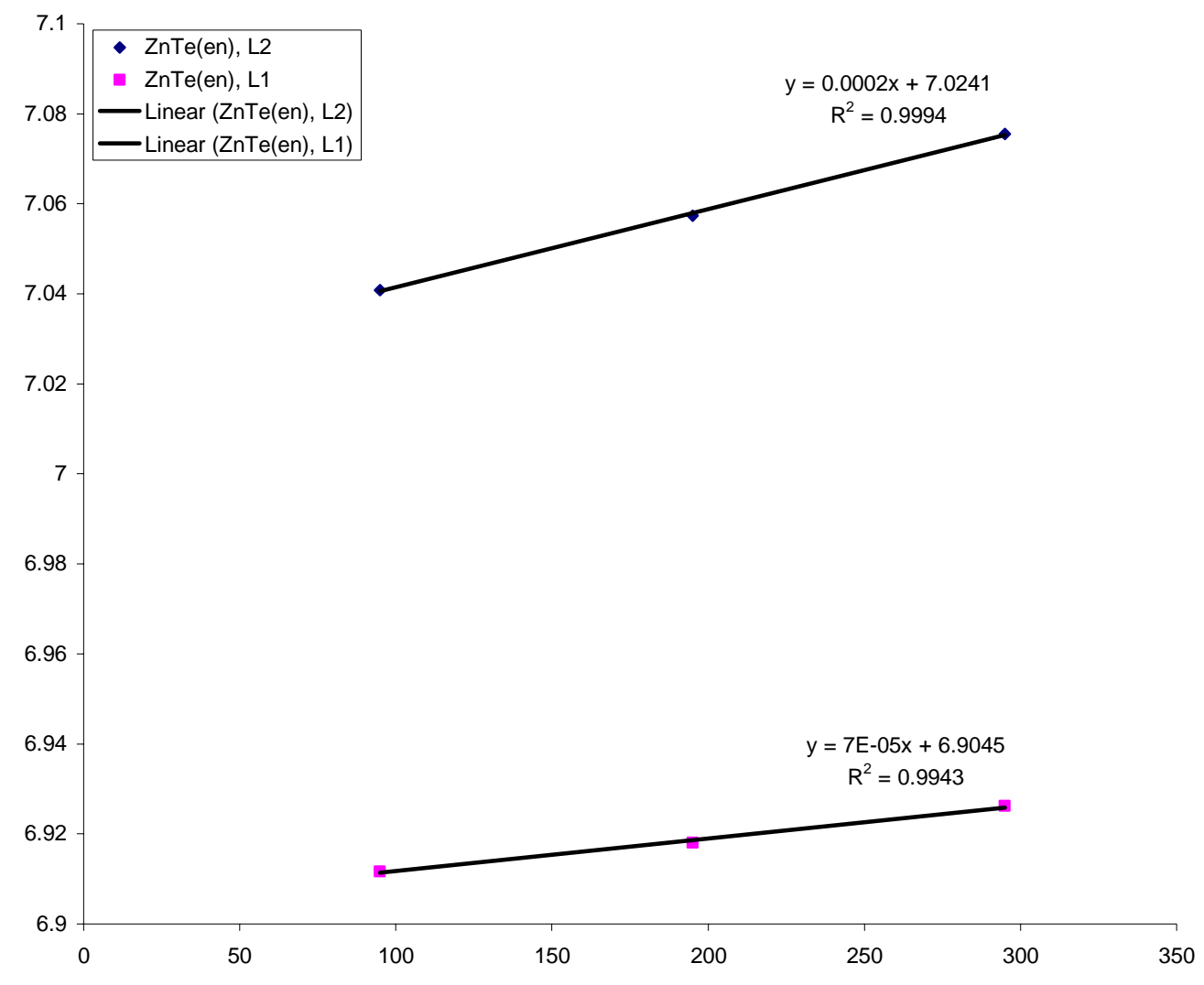




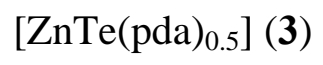

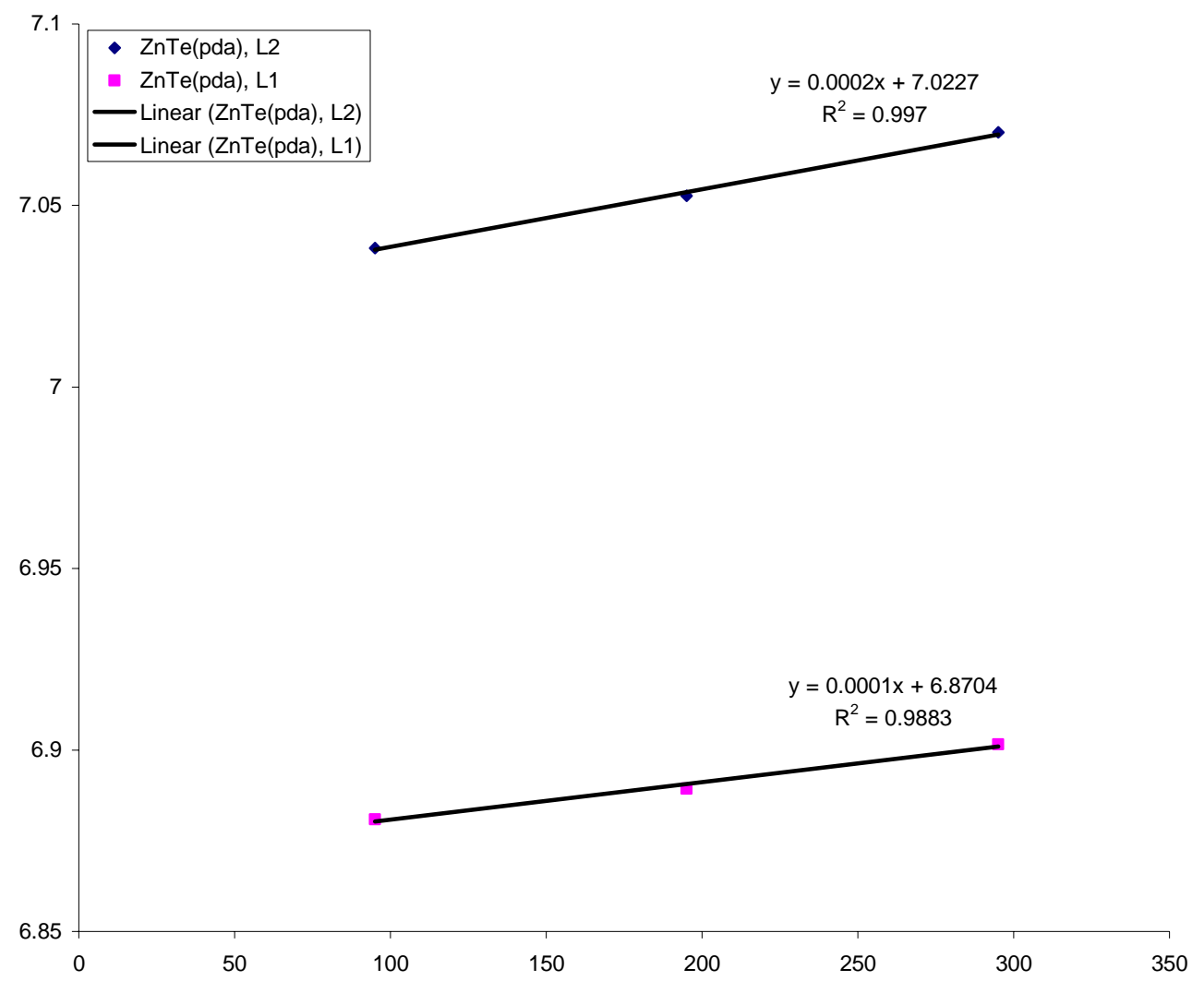


[ZnTe(bda) 0.5$]$ (4)

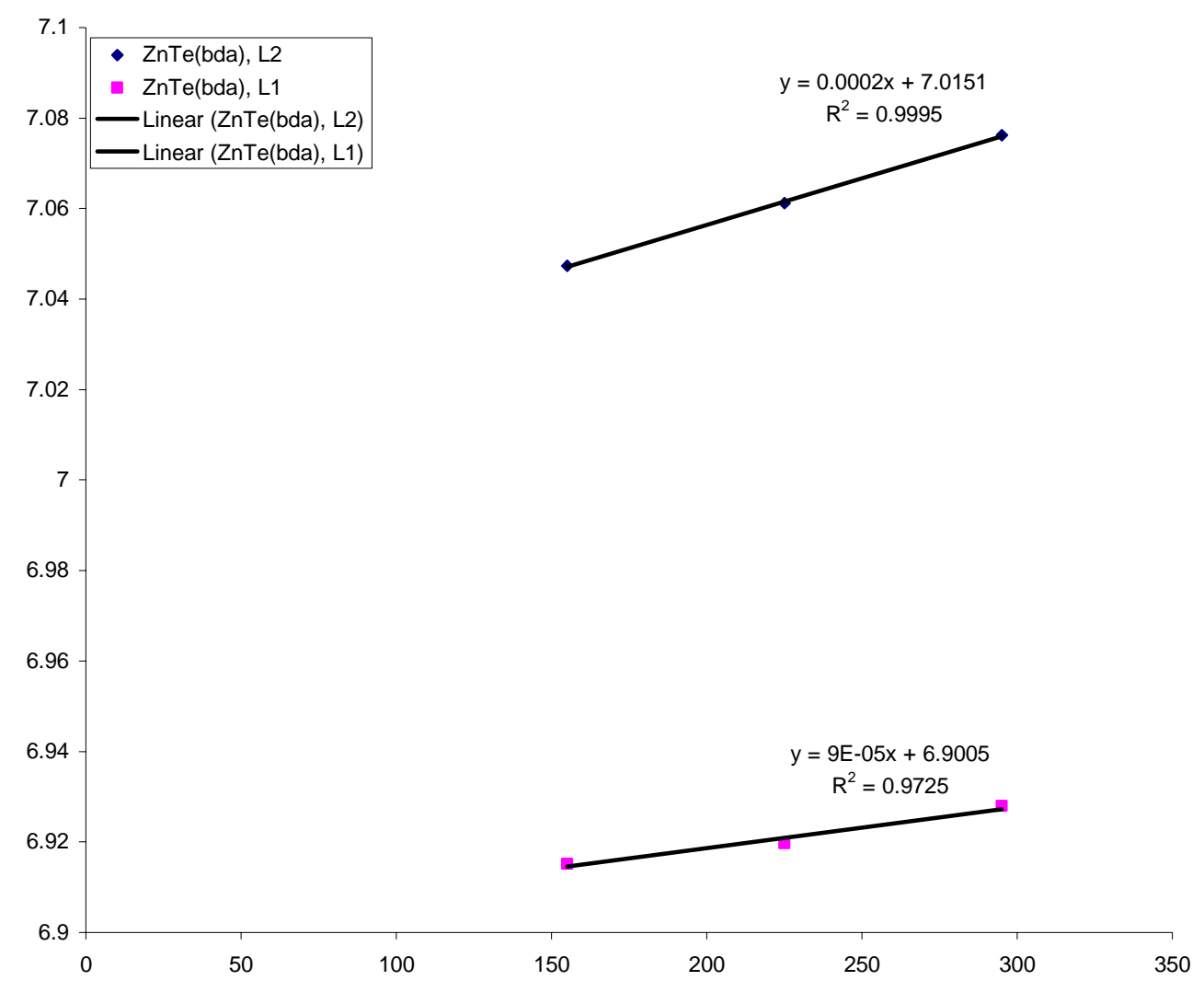


[ZnTe(ptda) $\left.{ }_{0.5}\right]$ (5)

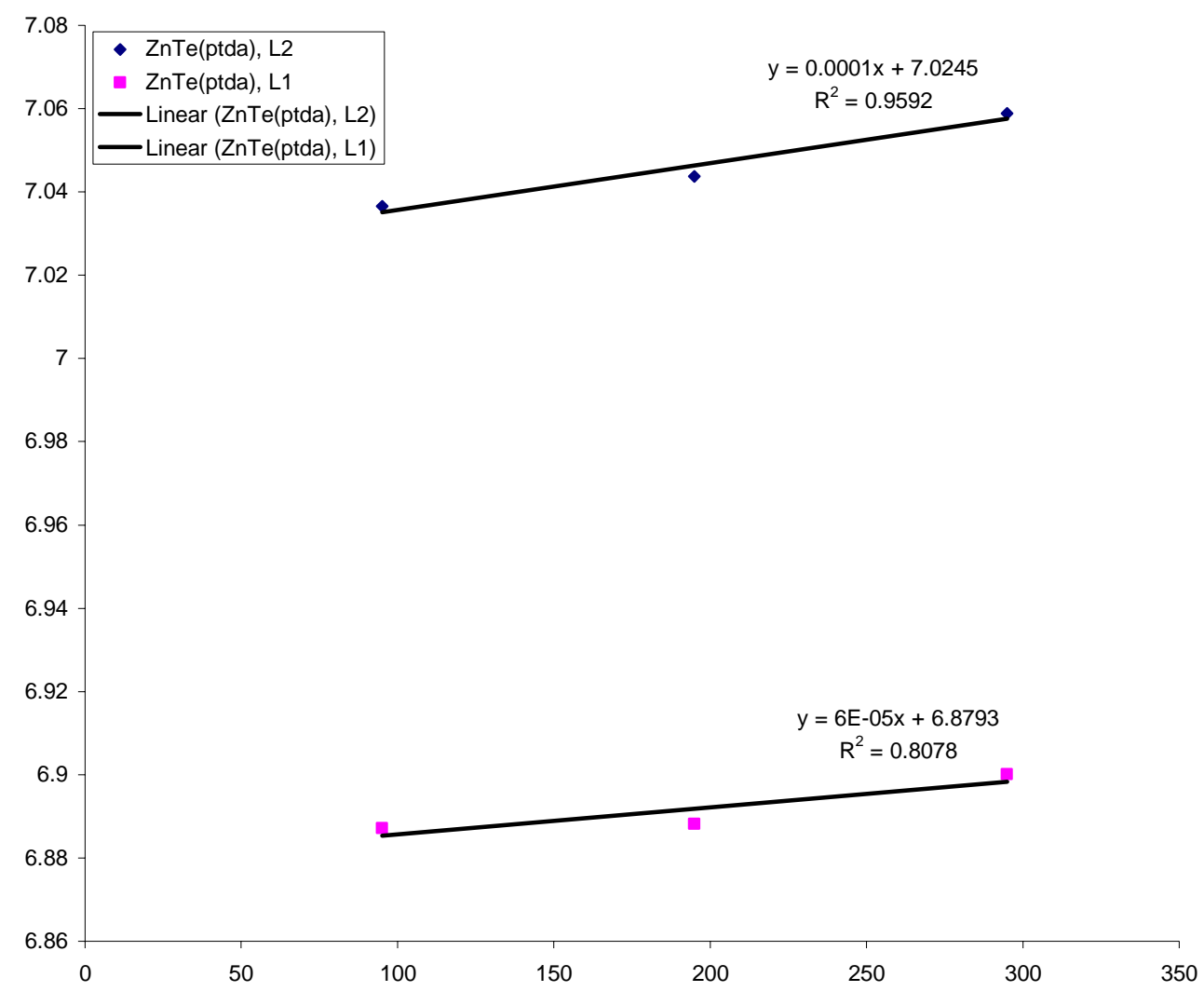


S.6. Figure 1 (Enlarged Version)

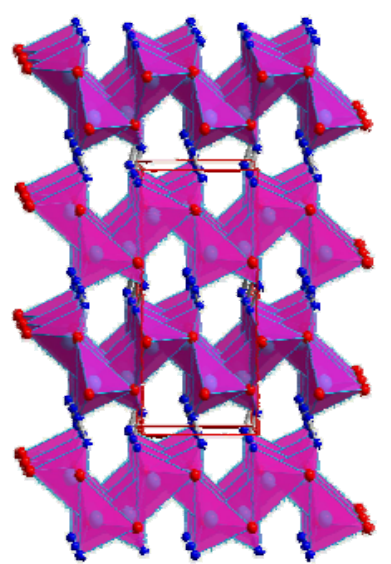

1

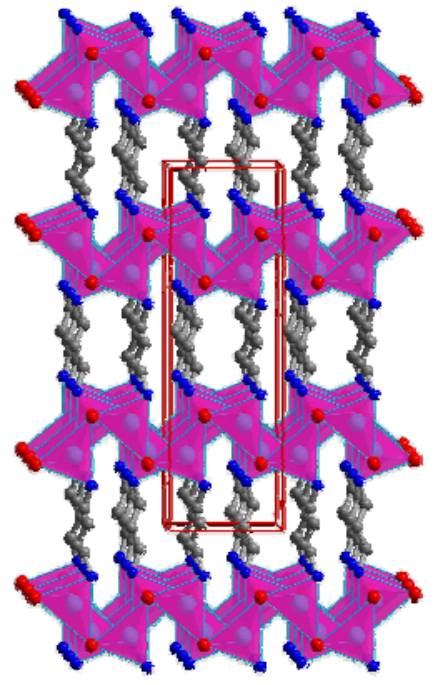

3

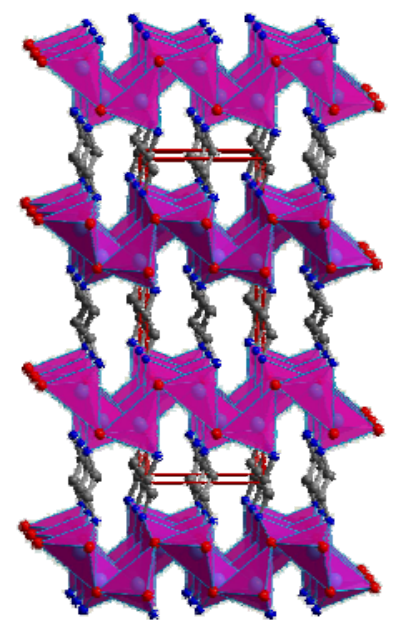

2

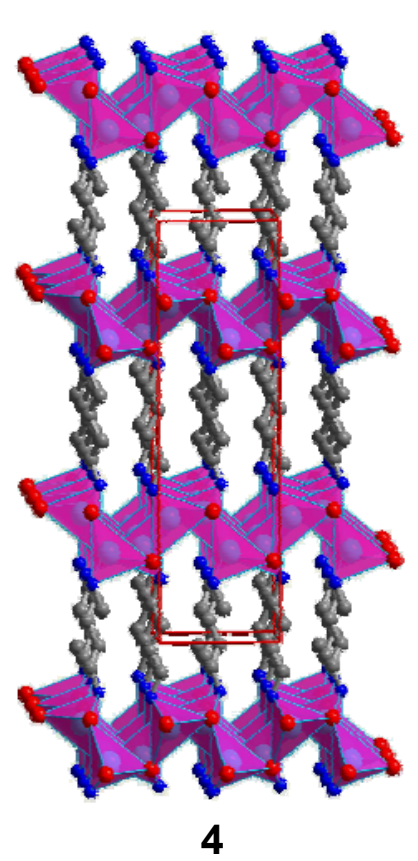

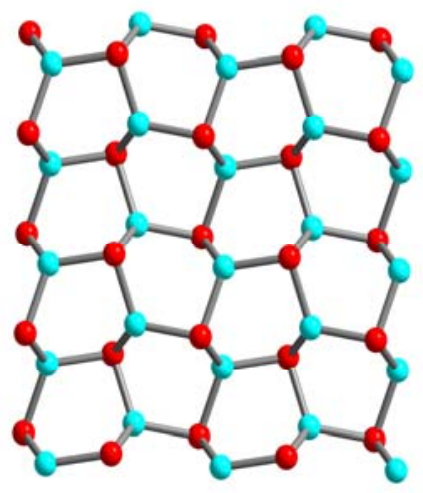

ZnTe Slab

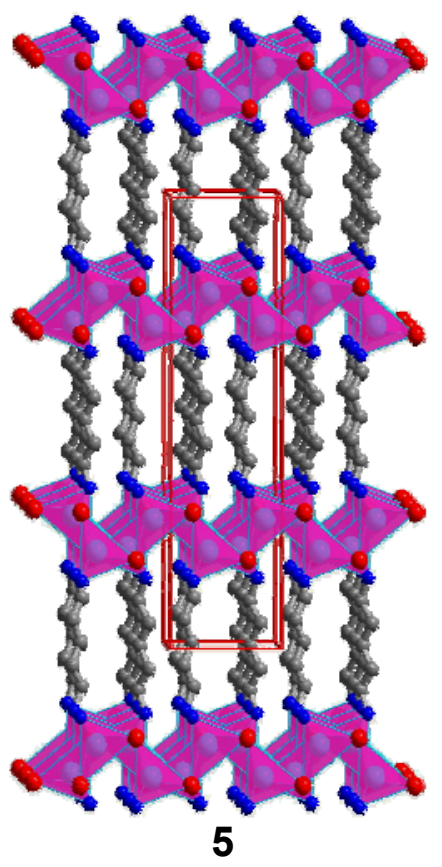


Figure 2b (Enlarge d Version)

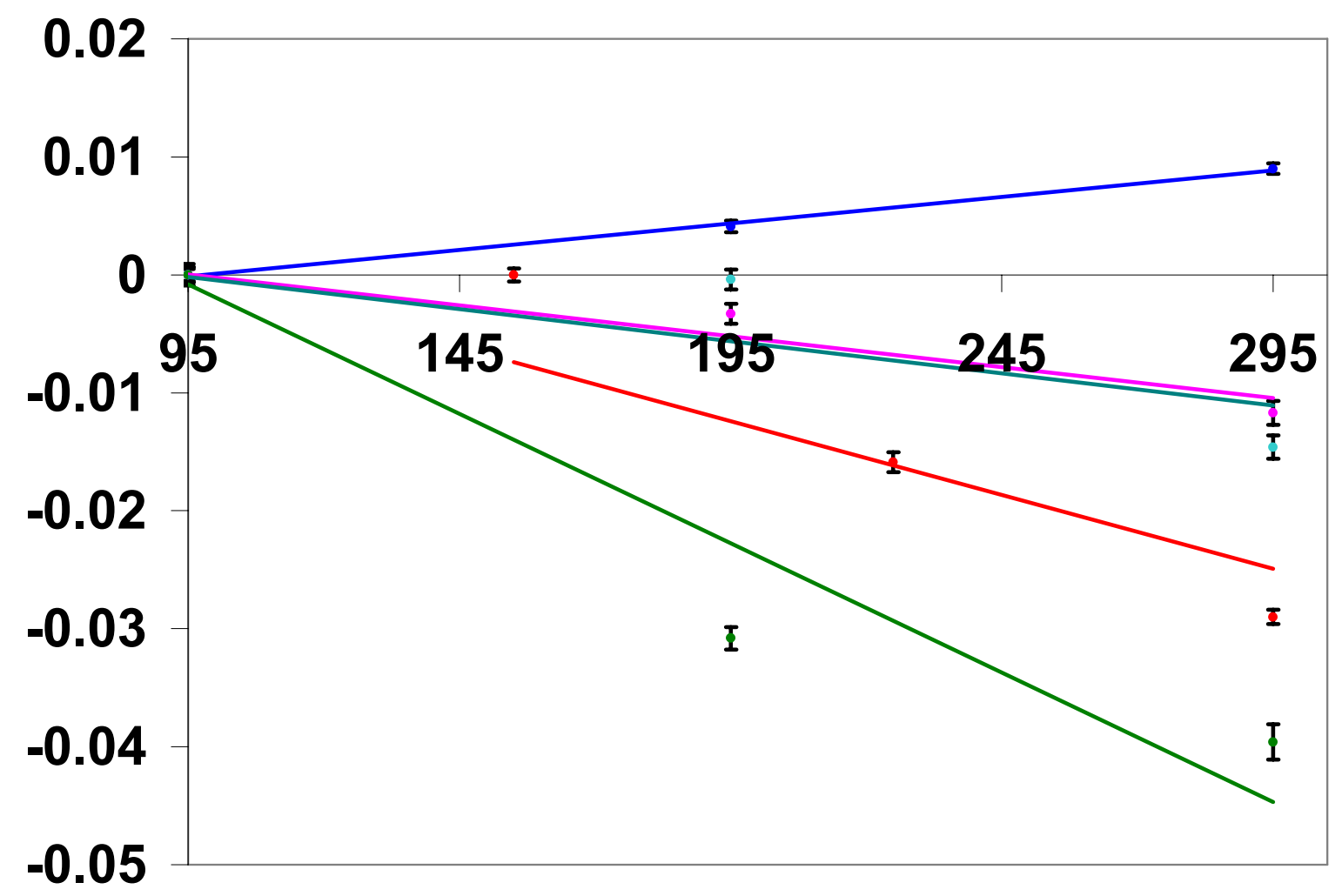


Figure 2c (Enlarged Version)

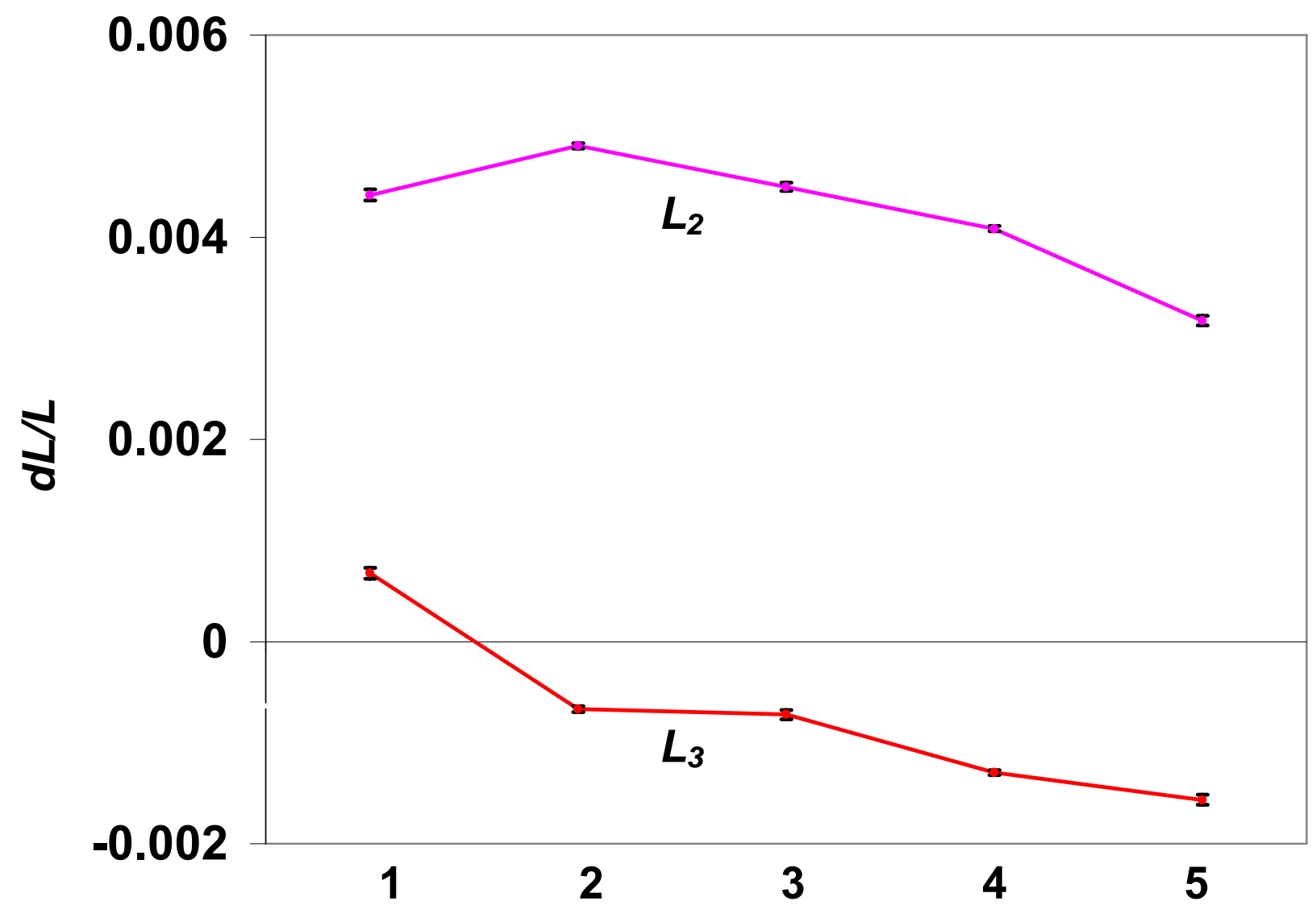




\section{S.7. Optical Absorption Spectra}

Optical diffuse reflectance experiments were performed at room temperature using a Shimadzu UV-3101PC double beam, double monochromator spectrophotometer. Data were collected in the wavelength range of $250-2000 \mathrm{~nm}$. $\mathrm{BaSO}_{4}$ powder was used as a standard (100\% reflectance). A similar procedure as previously described ${ }^{1}$ was used to collect and convert the data using the Kubelka-Munk function. ${ }^{2}$ The scattering coefficient $(S)$ was treated as a constant since the average particle size of the samples used in the measurements was significantly larger than $5 \mu \mathrm{m}$. Estimated band gap values are $2.1 \mathrm{eV}$ and 3.4-3.7 eV for ZnTe and 1-5, respectively.

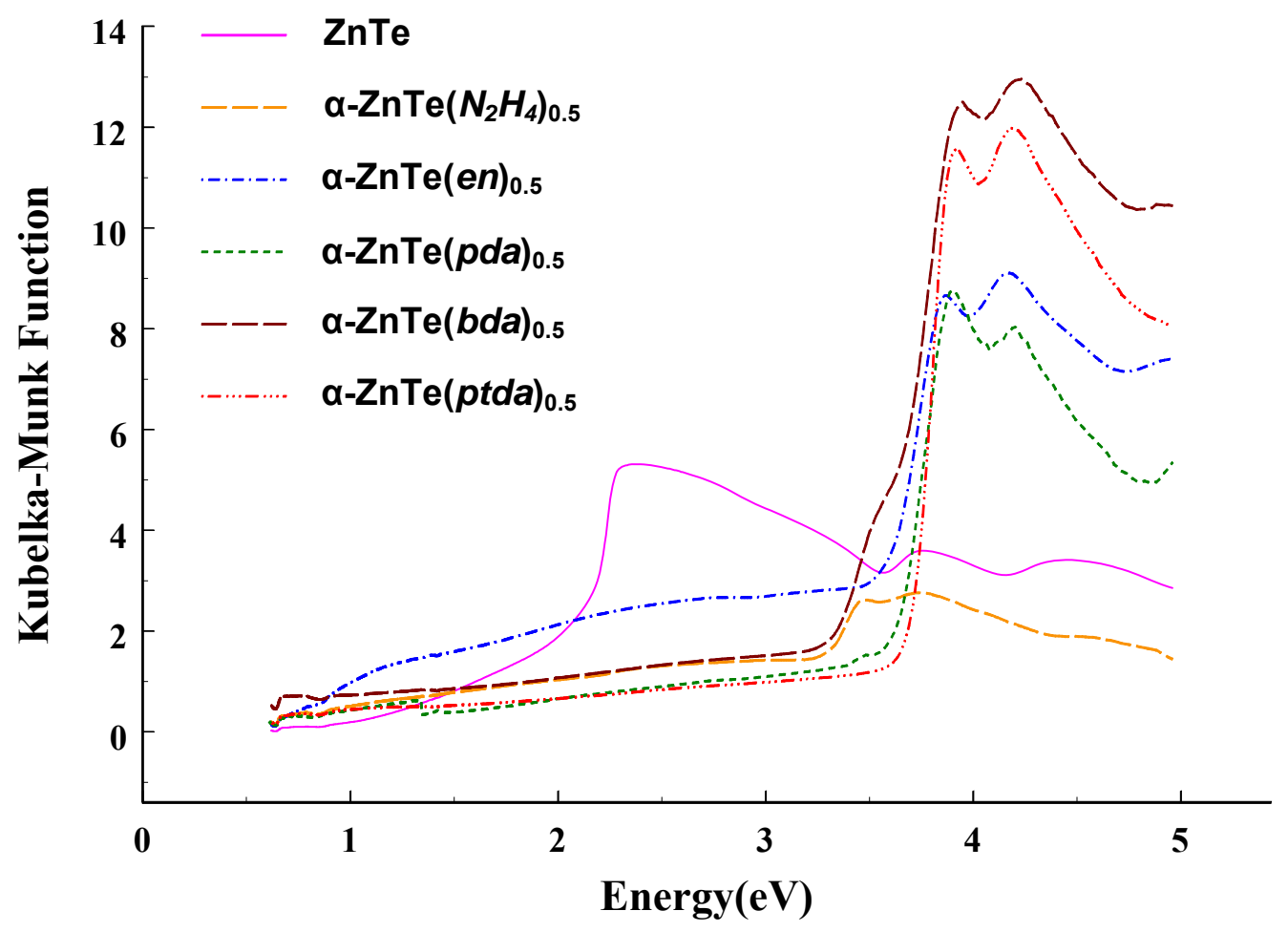




\section{S.8. Structure Comparison of $\alpha-\left[\operatorname{ZnTe}(e n)_{0.5}\right]$ and $\beta-\left[\operatorname{ZnTe}(e n)_{0.5}\right]$}

The crystal structure of $\beta$-[ZnTe(en $\left.)_{0.5}\right]$ is very similar to that of $\alpha$-[ZnTe(en $\left.)_{0.5}\right]$ (2), in that they have essentially the same bonding and connectivity with similar bond distances and angles. The main difference is that the II-VI slab in the $\alpha$-phase resembles more closely to the (110) face of the ZnTe wurtzite structure, while in the $\beta$-phase, it closely resembles the (110) face of the ZnTe zinc-blende structure. A view of each structure is shown below with the unit cell data at 295K indicated.
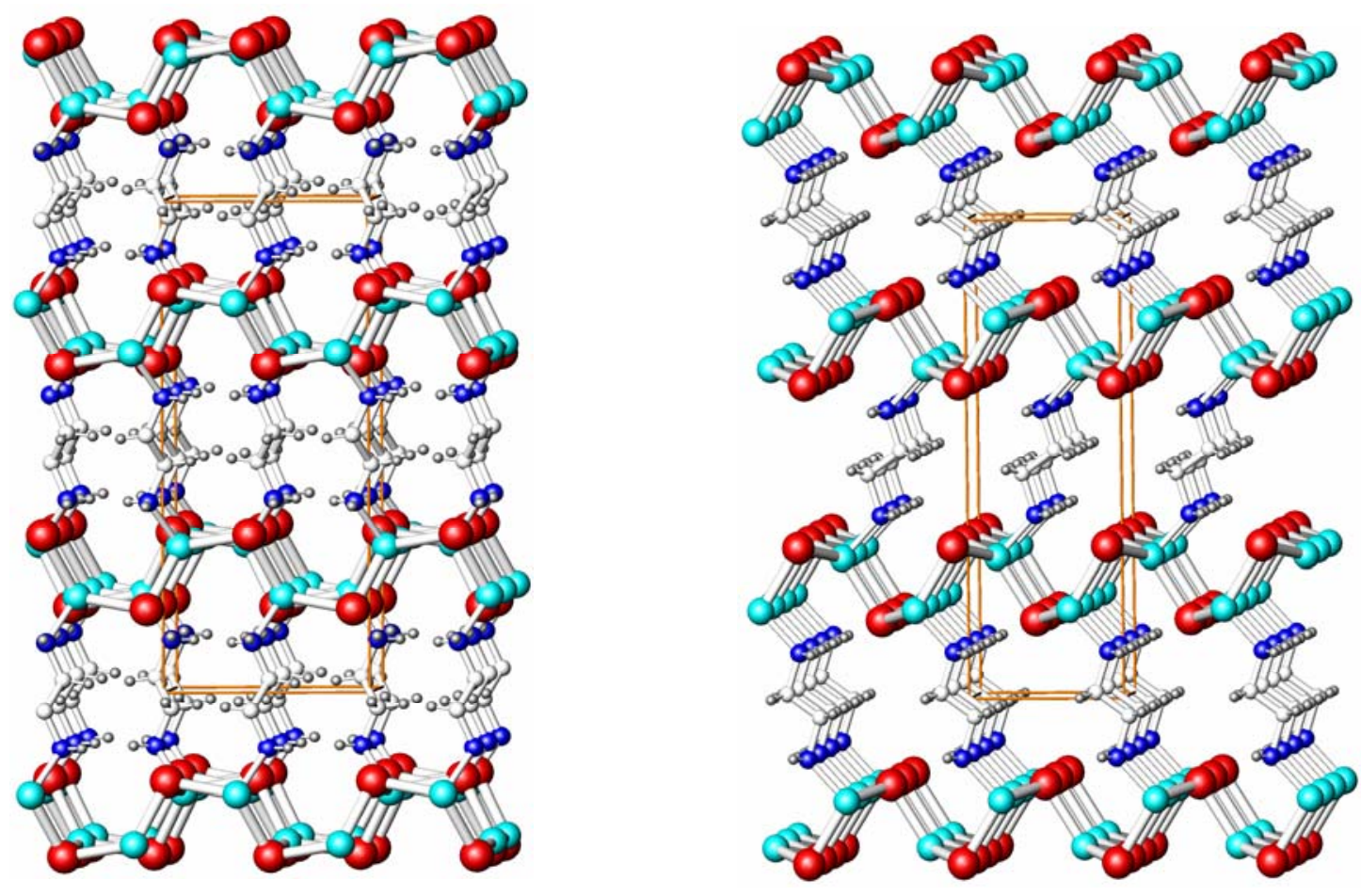

$$
\begin{gathered}
\alpha-\left[\operatorname{ZnTe}(\mathrm{en})_{0.5}\right] \\
P b c a \\
\mathrm{a}=7.0755(4) \AA \\
\mathrm{b}=6.9262(4) \AA \\
\mathrm{c}=17.5569(10) \AA
\end{gathered}
$$

$$
\begin{gathered}
\beta-\left[\mathrm{ZnTe}(\mathrm{en})_{0.5}\right] \\
\text { Pnnm } \\
\mathrm{a}=5.660(1) \AA \\
\mathrm{b}=17.156(3) \AA \\
\mathrm{c}=4.336(1) \AA
\end{gathered}
$$




\section{S.9. References}

1. Li, J.; Chen, Z.; Wang, X.-X.; Proserpio, D. M. J. Alloys Compd. 1997, 262-263, 28.

2. Wendlandt, W. WM.; Hecht, H. G. Reflectance Spectroscopy; Interscience, A Division of John Wiley \& Sons: New York, 1966. 